\title{
ARC Stent Thrombosis Timing Acute
}

National Cancer Institute

\section{Source}

National Cancer Institute. ARC Stent Thrombosis Timing Acute. NCI Thesaurus. Code C119594.

0 to 24 hours after stent implantation. (Cutlip DE, Windecker S, Mehran R, et al. Clinical Endpoints in Coronary Stent Trials : A Case for Standardized Definitions. Circulation. $2007 ; 115: 2344-2351)$ 